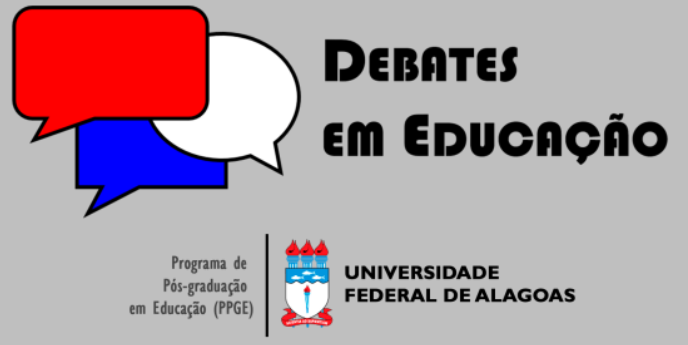

ISSN Eletrônico 2175-6600

Vol. 10 | No. 21 | Maio/Ago. | 2018

Fernando Silvio Cavalcante Pimentel

Universidade Federal de Alagoas (UFAL) prof.fernandoscp@gmail.com

\author{
Mônica Rejane de França Lima \\ (9) iD \\ Universidade Federal de Alagoas (UFAL) \\ monica.ufalara@hotmail.com
}

\section{EVASÃO NA EAD: O CASO DO CURSO DE PÓS-GRADUAÇÃO EM EDHDI/UFAL}

\section{RESUMO}

O presente trabalho tem como finalidade apresentar a investigação das causas principais da evasão no curso Especialização Educação em Direitos Humanos e Diversidade (EDHDI) na UFAL e contribuir para que, nas turmas posteriores esse problema venha a atenuar. A investigação de caráter exploratório, com abordagem quanto-qualitativa, utilizou-se de uma técnica de coleta de dados: um questionário com questões abertas e fechadas, tendo como objetivo investigar as causas principais da evasão no curso de especialização em Educação em Direitos Humanos e Diversidade (EDHDI) na Universidade Federal de Alagoas (UFAL), tendo como sujeitos os alunos não concluintes do curso que se iniciou em 2010. Na análise dos dados percebe-se que a falta de tempo e a deficiência quanto ao assessoramento realizado pelos tutores têm sido apontados como as grandes causas da desistência desses alunos. Desse modo, propõem-se estratégias de prevenção à evasão, como a capacitação dos tutores.

Palavras-chave: Evasão. Educação a Distância. Educação em Direitos Humanos.

\section{EVASION IN DISTANCE EDUCATION: THE CASE OF THE POSTGRADUATE COURSE IN EDHDI/UFAL}

\begin{abstract}
The present work aims to present the investigation of the main causes of evasion in the Specialization Education in Human Rights and Diversity (EDHDI) course at UFAL and contribute to the reduction of this problem in later classes. Exploratory research, with a qualitative approach, used data collection technique: a questionnaire with open and closed questions, aiming to investigate the main causes of evasion in the specialization course in Human Rights and Diversity Program (EDHDI) at Federal University of Alagoas (UFAL), with subject of study, students of non-final course that began in 2010. In the analysis of the data it is noticed that the lack of time and the deficiency regarding the advice made by the tutors have been pointed out as the major causes of the dropout of these students. In this way, strategies to prevent evasion, such as training tutors, are proposed.
\end{abstract}

Keywords: Evasion. Distance Education. Education in Human Rights.

Submetido em: 08/06/2017

Aceito em: 15/12/2017

DOI: 10.28998/2175-6600.2018v10n21p185-199 


\section{INTRODUÇÃO}

Numa sociedade em que o tema dos direitos humanos tem sido alvo de críticas banalizadas e sem fundamento, recorre-se a uma política de formação humana capaz de dirimir dúvidas, quebrar preconceitos e embasar conceitos antes construídos sem a compreensão crítica do tema.

Assim, surge o curso de especialização EDHDI que, de acordo com Alves e Ribeiro (2006), visa à qualificação crítica de profissionais em seus ambientes de trabalho, uma vez que essa qualificação deve ser guiada por fatores que conduzam a significados sociais e históricos da EDHDI, a fim de que o profissional possa ser agente da cultura dessa educação, respaldado em teorias e posicionamentos éticos e políticos.

Desse modo, a UFAL em parceria com outras universidades, vem ofertando, desde o ano de 2010, o curso de pós-graduação em EDHDI por meio de processo seletivo cuja modalidade é educação a distância (EAD) no formato semipresencial e já formou 229 especialistas nessa área.

Entretanto, um grande problema que vem assolando os cursos em EAD tem sido a evasão, na qual, devido a diversos fatores, um grande número de alunos ingressos não concluem o curso. Para tanto, foi necessário analisar o tema "evasão" nos cursos EAD para, posteriormente, investigar a realidade do curso em EDHDI na UFAL.

Dessa forma, este estudo tem como objetivo investigar as causas principais da evasão no curso de especialização em EDHDI na UFAL, tendo como objeto de estudo depoimentos de alunos não concluintes do curso que se iniciou em 2010, isto é, a primeira turma. De um universo de 196 alunos não concluintes, enviamos um questionário disponível em meio eletrônico para 166 e obtivemos o retorno de 80 alunos.

\section{EVASÃO EM CURSOS A DISTÂNCIA}

As rápidas e intensas transformações sociais e econômicas que perpassam o mundo do trabalho vêm exigindo investimentos em processos contínuos de aprendizagem que permitam a qualificação constante. Nesse contexto, a EAD, aparece cada vez mais presente na sociedade contemporânea.

De acordo com Belloni (2006) essa modalidade de educação surge como uma forma de atender às novas demandas educacionais decorrentes das mudanças causadas pela globalização, que não é apenas um fenômeno econômico, mas um processo de transformação do espaço e do tempo. 
Apesar de existir uma grande demanda de matrículas nessa modalidade de ensino, há, em contrapartida, um crescente número de evasão, tendo em vista alguns estudos apontados para essa problemática. Segundo Coelho (2004), as supostas causas quanto à evasão no curso a distância são: o insuficiente domínio técnico do uso do computador (principalmente da internet), falta da tradicional relação face a face entre professores e acadêmicos, dificuldade de expor ideias numa comunicação escrita a distância e a falta de um agrupamento de pessoas numa instituição física.

Adiante, veremos com mais profundidade as principais causas de evasão em cursos à distância de Educação em direitos humanos, trazendo à tona a realidade do referido curso na UFAL.

Foi a partir da Lei de Diretrizes e Bases da Educação Brasileira (LDB 9.394) que a educação a distância passou a ter existência legal, sendo reconhecida como modalidade de ensino por meio do artigo 80 que diz que: "O Poder Público incentivará o desenvolvimento e a veiculação de programas de ensino a distância, em todos os níveis e modalidades de ensino, e de educação continuada" (BRASIL, 1996). Após a regularização dessa modalidade de ensino houve uma crescente adesão das instituições de ensino superior na oferta do ensino à distância.

No contexto brasileiro, são consideradas diversas contribuições significativas para a consolidação da educação a distância no país, tais como os telecursos, a TV Escola, TVs Educativas, SENAI, SENAC, o Salto para o Futuro, voltado para a formação de professores e o surgimento de entidades de classe como a Associação Brasileira de Tecnologia Educacional (ABT), a Associação Brasileira de Educação a Distância (ABED) e o Instituto de Pesquisas Avançadas em Educação (IPAE).

Saviani (2008, p. 104) traz o seguinte conceito de EAD:

Considera-se educação a distância a forma de ensino que se baseia no estudo ativo independente e possibilita ao estudante a escolha dos horários, da duração e do local de estudo, combinando a veiculação de cursos com material didático de autoinstrução e dispensando ou reduzindo a exigência da presença.

As definições da EAD trazem a questão do distanciamento entre professores e alunos. Para Maia e Mattar (2007, p. 6) "é uma modalidade de educação em que os professores e alunos estão separados, planejada por instituições e que utiliza diversas tecnologias de comunicação". A não dependência da presença física entre mestre e aprendiz no mesmo espaço e tempo chamou a atenção da população adulta, com ênfase na autonomia do aluno.

Com o desenvolvimento tecnológico, o computador e a internet tornaram-se mídias de destaque, sendo cada vez mais disseminadas no meio educacional e social, 
ferramentas que possibilitaram a viabilização do ensino na modalidade virtual. Permitindo ao público a interação instantânea com textos, imagens, sons e a comunicação direta pelo sistema online, através de chats, fóruns, bate-papo, entre outros, aproxima os envolvidos no processo de ensino/aprendizagem.

Para Baird, Zampieri e Dias (2013) as Tecnologias da Informação e Comunicação (TICs) são importantes ferramentas utilizadas nos cursos de educação à distância que garantem a interação entre professores, tutores e alunos e ainda permite o uso de conteúdos disponíveis em outras mídias, além da criação de grupos de estudos e de produção colaborativa.

A modalidade EAD é uma alternativa interessante para quem pretende cursar o Ensino Superior (graduação e pós-graduação), principalmente, para aqueles que não tiveram oportunidade de fazer uma graduação logo que concluíram o Ensino Médio, ou para aqueles que não concluíram a educação básica e também os cursos profissionalizantes.

Conforme o Censo da EAD de 2012:

Em 2012, a idade da maioria dos alunos, nos cursos autorizados e disciplinas de EAD, em cursos autorizados, está na faixa de 18 a 30 anos $(50 \%)$ e 31 a 40 anos $(43 \%)$. A maioria dos alunos entre 18 e 30 anos está na graduação (33\%) e em ensino profissionalizante (24\%). A maioria dos alunos entre 31 a 40 anos está em curso superior de graduação (33\%) e superior de pós-graduação (34\%). (sic)

Os dados acima mostram que os alunos da EAD são majoritariamente formados pelo público adulto, e, consequentemente, já estão inseridos no mercado de trabalho, são trabalhadores que buscam capacitação e aperfeiçoamento, seja por meio do ensino profissionalizante, graduação ou pós-graduação.

Todavia, apesar dos milhares de alunos que estão matriculados e do número crescente de instituições que estão aderindo à EAD, a disseminação dessa modalidade de ensino tornou-se uma realidade que conquista cada vez mais adeptos, porém permanece um problema em comum a essa modalidade, a evasão.

Diversos autores tratam da evasão na EAD. Para Maia, Meirelles e Pela (2014), evasão refere-se à situação de alunos que não completam cursos ou programas de estudo, incluindo os que se matriculam e desistem antes mesmo de iniciar o curso. De acordo com Abbad, Carvalho e Zerbino (2006), o aluno evadido é aquele que desiste definitivamente do curso em qualquer etapa.

A problemática da não continuidade de um curso atinge tanto a rede privada quanto a pública; apesar do número crescente de matrículas na $E A D$, o número de alunos que não conclui os cursos é bastante relevante. Em pesquisa realizada a partir do Censo 
da Educação Superior em 2005, Lobo (2007) aponta que somente metade dos alunos que ingressam anualmente no sistema no Brasil obtêm a titulação no prazo previsto para a integralização dos estudos.

De acordo com Favero (2006) a evasão nos cursos EAD está ligada à falta da tradicional relação face a face entre professores e acadêmicos, insuficiente domínio técnico do uso do computador (principalmente da internet), dificuldade de expor ideias numa comunicação escrita à distância e a falta de um agrupamento de pessoas numa instituição física, dentre outros.

Abbad, Zerbini e Souza (2010) pontuam alguns elementos os quais favorecem a evasão. Esses elementos são vários e apontam para atividades diárias que se contrapõem à programação dos alunos, o que mostra que questões como falta de tempo, motivos pessoais, deslocamento de casa a um polo de estudo são entraves para a permanência no curso. Há também dificuldades de ordem tecnológica como o acesso aos aparatos tecnológicos; manuseio desses aparatos; internet, bem como fatores relacionados ao curso, dentre eles a complexidade do curso em si, a interação via tutor.

Uma das grandes dificuldades de um aluno que ingressa em um curso de EAD seria a falta de domínio das TICs, o que nos leva a entender que este necessita de uma formação prévia que o torne capaz de realizar grandes tarefas que envolvem habilidades com o computador/internet. No entanto, a sobrecarga no trabalho, que gera a falta de tempo para dedicar-se ao curso, e a falta de habilidade para administrar o tempo de estudo poderiam ser apontados como os principais elementos que favorecem a evasão.

A evasão é um impasse que prejudica as instituições de ensino (pública e privada), acarretando danos financeiros. Para manter cursos em ambiente virtual, são imprescindíveis investimentos financeiros e de pessoal. A discrepância entre o número de matriculados e a quantidade de concluintes de um curso pode levar ao insucesso do mesmo perante a sociedade, levando ao afastamento de novos interessados no curso.

Para Lobo (2007, p. 2):

[...] enquanto no setor privado de $2 \%$ a $6 \%$ das receitas das instituições de ensino superior - IES - são despendidos com marketing para atrair novos estudantes, nada parecido é investido para manter os alunos já matriculados. [...] são raríssimas as IES brasileiras que possuem um programa institucional profissionalizado de combate à evasão, com planejamento de ações, acompanhamento de resultados e coleta de experiências bem-sucedidas.

No cerne da discussão, percebemos que a grande incidência de evasão pode ser evitada, se cada instituição lançar o seu olhar para essa problemática e investir em 
projetos que sinalizem propostas que venham diminuir a quantidade de alunos não concluintes dos cursos de EAD.

\section{EDUCAÇÃO EM DIREITOS HUMANOS NA UFAL}

Diante da crescente necessidade de capacitação em educação em direitos humanos, a UFAL vem promovendo curso de pós-graduação lato sensu, EDHDI, direcionado a alunos e a outros profissionais da educação que atuem nas redes púbicas de ensino; profissionais da área de segurança pública; lideranças comunitárias e pesquisadores de outras categorias da demanda social ligados às áreas do Plano Nacional de Educação em Direitos Humanos (ALVES; RIBEIRO, 2013).

Nesse contexto, um dos objetivos que pautaram a criação do referido curso tem como princípio, segundo Alves; Ribeiro (2013, p. 364), "ratificar a importância e a necessidade de educar para formar cidadãos comprometidos com o processo de construção democrática de uma sociedade que prime por valores éticos".

Para tanto, buscou-se desenvolver uma parceria e interação entre as Instituições de Ensino Superior (IES) de cinco regiões do Brasil, tendo em vista, conforme os referidos autores (idem), "a efetivação de políticas públicas de educação pautadas pelo respeito à diversidade regional brasileira, e, ao mesmo tempo, na disseminação da EDH".

Desse modo, (ibidem) afirmam:

Trata-se de uma REDH, com a parceria do Fórum de Pró-Reitores de Extensão das Universidades Públicas Brasileiras - FORPROEX, envolvendo 15 IES, por meio de setores designados para responder pela EDH nos respectivos Estados, quais sejam: Rio Grande do Sul, Paraná, Rio de Janeiro, Espírito Santo, Minas Gerais, Mato Grosso do Sul, Goiás, Distrito Federal, Bahia, Sergipe, Alagoas, Amazonas, Amapá, Acre e Pará.

Percebe-se que o referido curso tem sido ofertado em pelo menos dois estados por região no Brasil o que nos leva a entender que, de maneira estratégica, tenta-se garantir a construção e efetivação de uma cultura em direitos humanos em todo o país, já que a realidade atual ainda é de que grande parte da população brasileira desconhece a complexidade dos direitos humanos.

O curso de especialização em EDHDI na UFAL tem como marco teórico o PNEDH que se destaca como política pública, fruto do compromisso do Estado com a efetivação dos direitos humanos e de uma construção histórica da sociedade civil organizada, e incorpora os conceitos de cidadania democrática, ativa e planetária cujos valores estão 
embasados nos princípios da liberdade, da igualdade, da equidade e da diversidade (BRASIL, 2007, p. 16).

Nesse sentido, Ribeiro e Ribeiro (2012, p. 36) acentuam que:

Num estado onde as diferenças econômicas são extremas e os índices sociais situam Alagoas entre os últimos colocados na qualidade de vida, oportunizar o aperfeiçoamento e a qualificação de docentes, que são multiplicadores de vários níveis sociais, é essencial para transcender esta cultura de fatalismo histórico, da falácia do imobilismo intelectual do povo, da exclusão, da indiferença diante da perpetuação das diferenças sociais e econômicas.

O educador tem papel fundamental na formação crítica do indivíduo perante as transformações sociais e situações de adversidade que o homem vem enfrentando atualmente, dentre elas a violação de seus direitos. Desse modo, formar e aperfeiçoar o conhecimento desse importante profissional é um passo fundamental na construção de uma sociedade que respeita a diversidade e complexidade existentes em sua natureza e na valorização do ser humano enquanto portador de direitos.

A educação em direitos humanos tem como cerne filosófico os princípios e valores que permeiam a dignidade humana. Nesse sentido, o professor deve basear-se numa prática que priorize conteúdos que estimulem o respeito e a consciência de tais direitos, além de despertar a indignação do aluno frente às injustiças e aos atos que violam a dignidade humana. Portanto, a educação em direitos humanos aspira por prevenir a violência e promover uma cultura de paz e de direitos humanos dentro e fora das escolas (TAVARES, 2007).

É notório que a educação assume um importante papel na promoção dos direitos humanos. Para tanto, em 2004, foi sistematizado o Plano Nacional de Educação em Direitos Humanos (PNEDH), que visava, segundo Ribeiro e Ribeiro (2012, p. 278), "articular a discussão acerca de políticas, ações e programas, comprometidos com a disseminação de uma cultura de respeito aos direitos da pessoa humana".

A escola, de acordo com PNEDH (2007), adquire um papel especial em sua atuação, visto que contribui para a realização de ações educativas que visem fomentar, promover e estimular a cultura dos direitos humanos tendo em vista o seu fortalecimento no espaço escolar, favorecendo o combate das diversas formas de discriminação e violação dos direitos.

Para melhor trabalhar a EDHDI, O PNEDH se dividiu-se em várias temáticas, instituindo percepções, objetivos, diretrizes, princípios e linhas de ação, os quais contemplam "cinco grandes eixos de atuação: Educação Básica; Educação Superior; Educação Não-Formal; Educação dos Profissionais dos Sistemas de Justiça e Segurança 
Pública e Educação e Mídia" (BRASIL, 2007, p. 25). A partir de tal documento é possível compreender que a educação no cenário brasileiro é entendida como um direito e um meio imprescindível para o acesso a outros direitos, sendo direcionada ao total desenvolvimento humano, em relação com outras áreas e concentração de estudos.

A partir do PNEDH vários projetos e programas estão sendo criados pelo o Estado Democrático, para formar educadores e gestores nesse sentido.

A conquista do Estado Democrático delineou, para as Instituições de Ensino Superior (IES), a urgência em participar da construção de uma cultura de promoção, proteção, defesa e reparação dos direitos humanos, por meio de ações interdisciplinares, com formas diferentes de relacionar as múltiplas áreas do conhecimento humano com seus saberes e práticas. Nesse contexto, inúmeras iniciativas foram realizadas no Brasil, introduzindo a temática dos direitos humanos nas atividades do ensino de graduação e pós-graduação, pesquisa e extensão, além de iniciativas de caráter cultural (BRASIL, 2007, p. 37)

Na busca dessa construção de uma cultura de promoção dos direitos humanos, as instituições desenvolveram cursos de especialização e aperfeiçoamento. Sendo assim, também a Educação Superior vem-se comprometendo na construção de uma cultura de respeito aos direitos humanos e à diversidade.

Os especialistas em EDHDI recebem formação que contribui para sua atuação profissional, respeitando e comprometendo-se com os valores e princípios éticos norteadores do PNEDH, ampliando a sua capacidade crítica de análise e propositiva nos variados campos de atuação. A capacitação na área dos direitos humanos traz para a sociedade alagoana colaborações significativas para a concretização da educação em direitos humanos acessível a todos.

As IES têm desenvolvido expressivamente seu papel, mediante critérios de excelência e relevância social, tendo por fim a prestação de contas à sociedade. A UFAL, notadamente, vem desempenhando seu papel como agente disseminador da EDHDI. Segundo Alves e Ribeiro (2013, p. 364), "Até o momento já formou 229 especialistas em EDHDI na primeira turma e 131 em vias de finalização da segunda turma, além de 220 graduandos na disciplina de EDH oferecidas nos cursos de Pedagogia e Serviço Social"1.

Ao longo do período entre 2009 e 2013, a UFAL ampliou a oferta do Curso EDHDI para um total de cinco polos, localizados na região do agreste, do sertão e do litoral do Estado de Alagoas. Desse modo, abrangendo o número de municípios com especialistas em direitos humanos, a interiorização dos polos possibilitou o ingresso de alunos das cidades interioranas.

\footnotetext{
${ }^{1}$ A citação de Alves e Ribeiro se refere ao ano de 2013, quando o texto desses autores foi publicado.
} 
É pertinente ressaltar que o empenho coletivo já registra saldo positivo, podemos citar: especialistas formados na turma inicial vêm implantando em algumas escolas da rede pública disciplinas de EDHDI. Contamos ainda com a inclusão da educação em direitos humanos nos projetos pedagógicos de curso e nos planos de atividades de alguns municípios cúmplices no processo por profissionais capacitados pela AEDHESP, de modo que autoridades e população envolvidas já demonstram suas pretensões na continuidade das ações educação em direitos humanos.

A seguir, trataremos da evasão no Curso EDHDI, visto que, da mesma forma que outros cursos de especialização a EAD, encontra, neste problema, um grande empecilho para o total êxito do curso. Em uma pesquisa da Fundação Getúlio Vargas, ao analisar durante três anos um universo de instituições brasileiras de ensino superior, que oferecem cursos online ou semi-presenciais, ficou evidente que os cursos com maior índice de evasão são os de extensão e especialização, que chegam a 25\% de abandono (MAIA, MEIRELLE; PELA, 2014).

\section{EVASÃO NO CURSO EDHDI/UFAL}

Vimos que a evasão é fruto de uma série de fatores, como pontuou Abbad, Zerbino e Souza (2010). Desse modo, a partir da investigação realizada com os evadidos do curso EDHDI, alguns condicionantes confirmam, contestam ou acrescentam essa lista de fatores.

A investigação de caráter exploratório, com abordagem quanto-qualitativa, utilizouse de uma técnica de coleta de dados: um questionário com questões abertas e fechadas.

Foram convidados a participar da pesquisa 166 alunos, considerados evadidos do curso de especialização EDHDI de 2010 a 2012, sendo esses da primeira turma, estando a segunda turma em processo de finalização do curso, não foi possível termos acesso aos dados. Do total de participantes, aproximadamente $48 \%$ responderam ao questionário disponibilizado por meio eletrônico entre o período de 12/02/2014 a 23/02/2014.

Analisando os dados coletados, verificou-se que o percentual do gênero feminino, que se evadiu do curso, chega a $74 \%$ e o índice masculino correspondeu a aproximadamente um terço disso, 26\%. Dessa forma, o que se pode constatar é que o maior número de ingressantes é representado pelo gênero feminino, sendo esses dados baseados no edital de convocação, é também onde ocorre a maior incidência de evasão.

Em pesquisa realizada com alunos do curso de biologia à distância de uma universidade pública com o objetivo de identificar as principais causas da evasão do curso 
em questão, o gênero feminino também vem sendo apontado como aquele em que há mais incidência de desistência em curso de EAD, na qual Santos e Oliveira Neto (2009) pontuam que, talvez essa desistência significativa dos sujeitos do sexo feminino, esteja relacionada com a própria condição atual da mulher, que acumula várias atividades no trabalho e em casa, cumprindo seu papel de esposa, dona de casa e mãe.

O gráfico 1 comprova que a maior concentração de alunos evadidos ocorreu na faixa etária de 31 a 35 anos; seguidos da faixa de 26 a 30 anos. Tal resultado nos faz refletir sobre o perfil do aluno nessa faixa etária, já que esse possui muitas responsabilidades e atribuições, além do estudo.

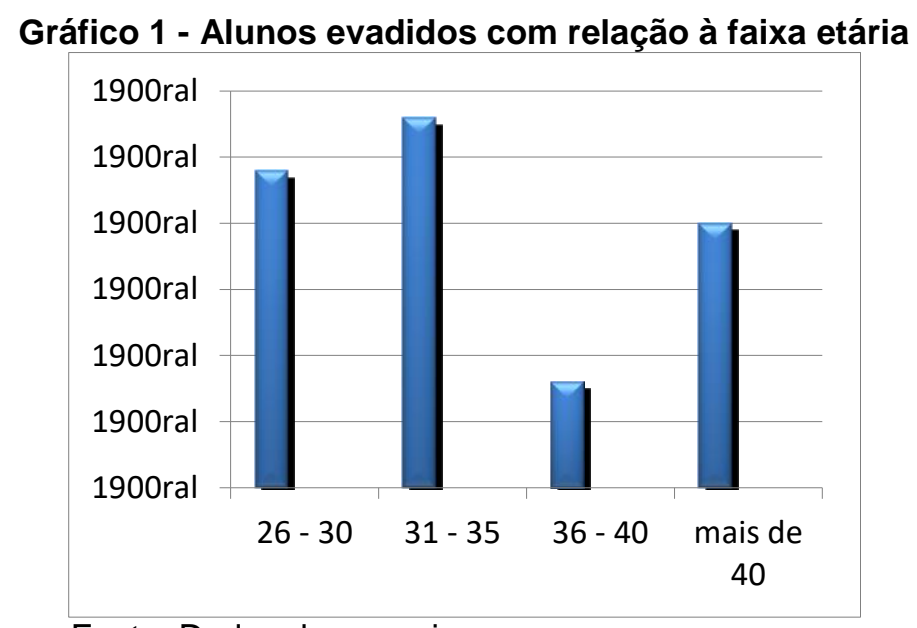

Fonte: Dados da pesquisa

Corroborando com o resultado obtido, Bastos e Silva (2009) alegam que um dos principais fatores determinantes para a evasão é o cansaço dos alunos que, em sua maioria, trabalham durante o dia e ficam com tempo indisponível para a realização das tarefas adequadamente, mas por outro lado, a procura de cursos online se dá devido ao contato desse público com o meio digital.

As causas que desmotivam um aluno do curso de pós-graduação semipresencial a prosseguir em seus estudos são diversos, assim enfatizando as mais comumente apontadas na evasão no curso EDHDI estão representadas no gráfico a seguir. 


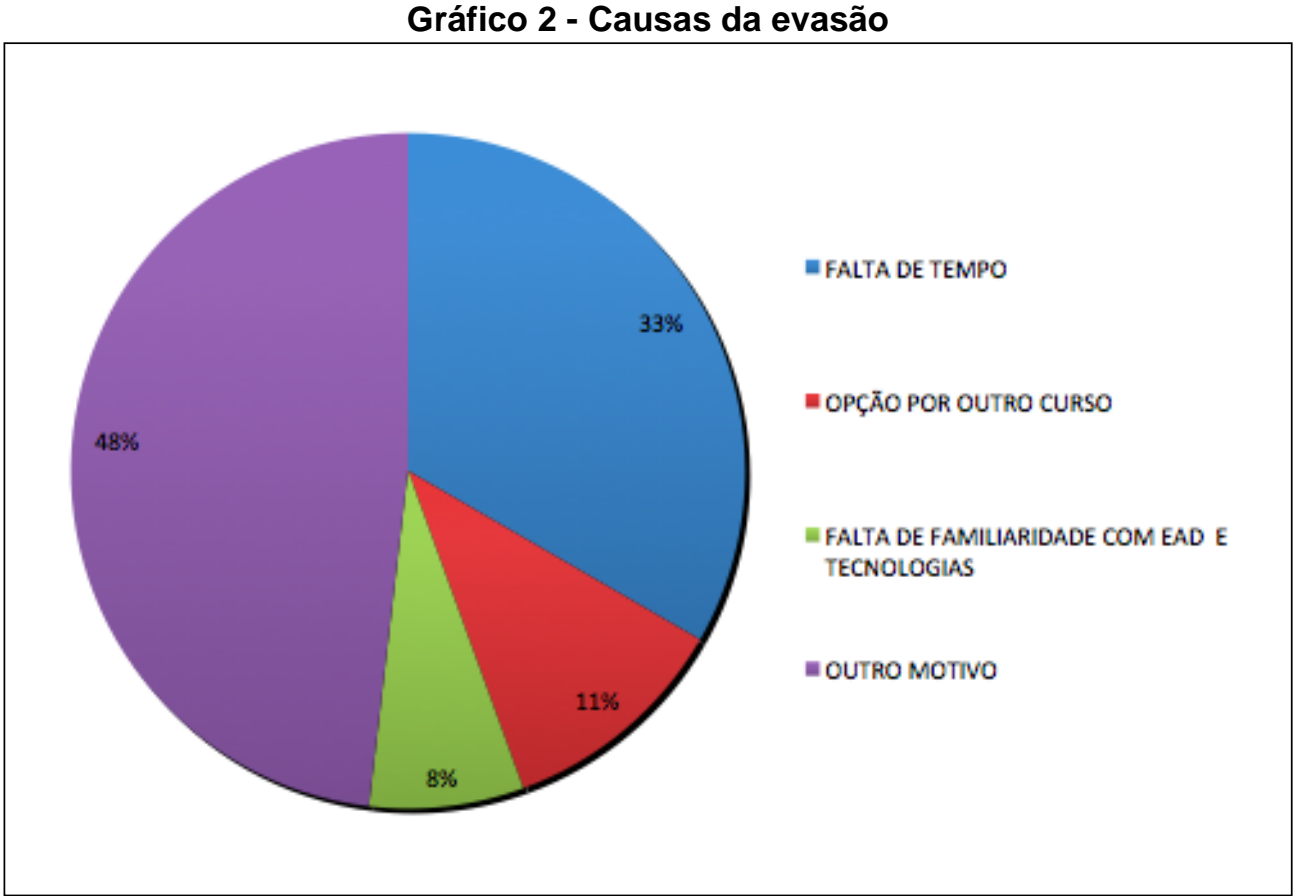

Fonte: Dados da pesquisa

Observando que grande parte dos alunos evadidos alegou que não dispõe de tempo suficiente para realizar as atividades propostas pelo curso, ratificamos o que foi afirmado anteriormente: que os alunos, em sua maioria, possuem outras responsabilidades que interferem de maneira direta na continuidade do curso, chegando a atingir um percentual de 33\% que justificou ser essa a causa da evasão. Para a aluna A o curso de especialização EAD seria adequado a sua rotina corrida, entretanto, ao longo do curso, tornou-se evidente que as responsabilidades não se diferenciavam do curso presencial, conforme a resposta da referida aluna:

Como não tinha muito tempo para realizar uma pós-graduação presencial, achei que fazer uma pós-graduação à distância seria menos corrido. [...] Com as mudanças que ocorreram ao longo do curso, se tornou mais complexa do que uma pós presencial, pois além das aulas presenciais, havia a necessidade de se frequentar o ambiente virtual, postar informações no blog, responder material virtual, entre outros... (ALUNA A)

Outro motivo apontado como causa da evasão de alunos na EDHDI seria a questão da falta de familiaridade com a EAD e as TIC. Nesse aspecto, buscamos verificar a capacidade de comunicação e acesso permanente, desses alunos, bem como sua habilidade em lidar com as TIC e constatamos que alguns alunos se mostraram impossibilitados de manter uma conexão diária com todas as informações concernentes ao curso, uma vez que alguns acessavam apenas durante a semana em seu ambiente de trabalho ou mesmo em lan house e também alguns afirmaram ter dificuldade no manejo 
dessas ferramentas. Sobre essa questão, verificamos um percentual de $8 \%$, tal como destaca a aluna $B$.

Tive dificuldade em acessar a plataforma moodle, pois ela continha muitas informações ao mesmo tempo (...). Assim, abandonei o curso, pois não tinha condições de levá-lo adiante. (ALUNA B)

Uma das razões de desistência de um curso tem como raiz a opção por outro curso, seja pela não adaptação ao mesmo ou também pela perda de interesse pelo assunto. Além disso, ao optar por outro curso, o aluno quer revelar que o mesmo não vem satisfazendo às suas necessidades de formação ou que não possui afinidade com a área. Desse modo, $11 \%$ responderam que o motivo da evasão foi a opção por outro curso, conforme a aluna $\mathrm{C}$.

Num primeiro momento, achei que o curso seria interessante, mas com o passar do tempo fui me desestimulando, pois o mesmo trazia abordagens que trazia muitas referências à sala de aula. Como não sou professora, escolhi fazer outra especialização. (ALUNA C)

Na presente pesquisa, a maior porcentagem com relação às causas da evasão foi citando outros motivos (gráfico 2), sendo que, pontuando-se a falta ou deficiência de assessoramento do tutor como o principal destes. No entanto, outros problemas mencionados foram: a cobrança de trabalhos em grupos e mais de uma aula presencial por módulo.

\footnotetext{
Faltou orientação por parte dos tutores, acredito que por ser a primeira turma e ter muitos alunos em mais de um núcleo, fomos penalizados com a falta de experiência e organização. (Aluno D)

Falta de apoio por parte da equipe da universidade, apoio dos tutores, enfim. (Aluno E)

Inicialmente só deveria fazer uma aula presencial por módulo, posteriormente passou para duas aulas, também passaram a ser cobrados trabalhos em grupo, com pessoas que a gente não tinha muito contato até porque o curso é a distância e se tem pouco contato com outros alunos. (Aluna F)
}

Essa questão apresentada pela Aluna F, sobre a quantidade de trabalhos, pode estar vinculada ao planejamento realizado pela coordenação do curso junto aos professores, sendo os tutores apenas colaboradores do processo de ensinoaprendizagem. Em análise da fala do Aluno D, é mencionado que havia muitos alunos por núcleo, o que pode ser atribuído também a uma problemática de gestão.

Apesar dos motivos descritos acima terem sido apontados como as principais causas da evasão de alunos no curso de especialização em EDHDI, não podemos deixar de descartar que é a união dos vários fatores que colaboram para que o aluno não 
consiga concluir o curso. Portanto, para entender as causas da evasão nos cursos, de uma forma geral, é necessário observar a complexidade e o conjunto de motivações que levam os alunos a desistirem de obter uma melhor formação acadêmica.

\section{CONSIDERAÇÕES FINAIS}

Esta investigação procurou identificar as principais causas da evasão no curso de pós-graduação em EDHDI, e espera-se que, de alguma forma, possa contribuir para a diminuição do número de alunos evadidos, já que o índice apontado foi bastante relevante, e as causas variam entre internas e externas ao curso.

A partir dos dados coletados é possível identificar os seguintes motivos para a evasão, no curso avaliado: tempo insuficiente para realizar as atividades propostas pelo curso; a falta de familiaridade com a EAD e as TIC; a opção por outro curso; a falta ou deficiência de assessoramento do tutor; a cobrança de trabalhos em grupos; a necessidade de mais aulas presenciais por módulo.

Desse modo, propõem-se estratégias de prevenção à evasão, como a capacitação efetiva para os tutores à distância e presenciais, sendo 0 tutor 0 elo entre professor/tutor/aluno na orientação e supervisão do ensino-aprendizagem. Também, a partir do que indicam as falas de alguns alunos, é significativo que as equipes gestoras possam estar atentas às demandas, observando a situação da quantidade de alunos por polo, por exemplo.

Outra estratégia seria a oferta de cursos de nivelamento no início da especialização, visando sanar as dificuldades com as TIC e o Moodle, para que os alunos obtenham domínio técnico necessário para atuar com habilidade e aptidão, no espaço que está utilizando. No momento da matricula disponibilizar uma cartilha contendo os requisitos necessários para a EDHDI, assim evitando decepções quanto às expectativas iniciais.

É preciso aperfeiçoar cada vez mais a metodologia da EAD, possibilitando oportunidades e investindo em pesquisas voltadas para metodologias pedagógicas mais eficazes, capazes de especializar mais pessoas e reduzir a evasão.

\section{REFERÊNCIAS}

ABBAD, G. S.; ZERBINI, T.; SOUZA, D. B. L. Panorama das pesquisas em educação a distância no Brasil. Estudos de Psicologia, online, Natal, v. 15, n. 3, set./dez. 2010. 
Disponível em: < http://www.scielo.br/pdf/epsic/v15n3/a09v15n3.pdf>. Acesso em: 18 fev. 2014.

ABBAD, G. S.; CARVALHO, R. S.; ZERBINI, T. Evasão em Curso a Distância via Internet: Explorando Variáveis Explicativas. RAE-eletrônica, v. 5, n. 2, Art. 17, jul./dez. 2006. Disponível em: $<$ http://www.scielo.br/scielo.php?pid=S167656482006000200008\&script=sci arttext>. Acesso em: 07 fev. 2014.

ALVES, J. ; RIBEIRO, M. (org.). A encruzilhada da diversidade no âmbito da EDH. Maceió: EDUFAL, 2013.

BAIRD, R. R. P.; ZAMPIERI, P. N. A.; DIAS, C. A problemática da evasão no processo de implantação do curso técnico em serviços Público a distância em Mato Grosso do Sul. ESUD 2013 - CONGRESSO BRASILEIRO DE ENSINO SUPERIOR A DISTÂNCIA BELÉM/PA. X, 2013. BELÉM/PA. UNIREDE.

BASTOS, H. P. P.; SILVA, J. M. Fatores de evasão em curso a distância: Relato de Pesquisa sobre Evadidos do Curso "Leitura Instrumental em Inglês a Distância" no IFF, RJ. RENOTE - Revista Novas Tecnologias na Educação. v. 7, n. 3, 2009. Disponível em: <file:///C:/Users/M\%C3\%B4nica/Downloads/13516-52645-1-PB.pdf>. Acesso em: 23 fev. 2014.

BELLONI, M. L. Educação a distância. Campinas: Editora Autores Associados, 2006.

BRASIL. Plano Nacional de Educação em Direitos Humanos / Comitê Nacional de Educação em Direitos Humanos. Brasília: Secretaria Especial dos Direitos Humanos, Ministério da Educação, Ministério da Justiça, UNESCO, 2007. Disponível em: <http://portal.mj.gov.br/sedh/edh/pnedhpor.pdf>. Acesso em: 20 fev. 2014.

Lei de diretrizes e bases da educação (Lei n. 9.394). Diário Oficial da União, Brasília, 20 dez. 1996.

COELHO, M. L. A Evasão nos Cursos de Formação Continuada de Professores Universitários na Modalidade de Educação a Distância Via Internet. Associação Brasileira de Educação a Distância - ABED, 2014. Disponível em:

<http://www.abed.org.br/site/pt/midiateca/textos_ead/626/2004/12/a_evasao_nos_curso s_de_formacao_continuada_de_professores_universitarios_na_modalidade_de_educac ao_a_distancia_via_internet_>. Acesso em: 09 fev. 2014.

CENSO EAD. BR: Relatório Analítico da Aprendizagem a Distância no Brasil $2012=$ Censo EAD. BR: Analytic Reporof Distance Learning in Brazil - Curitiba: Ibpex, 2013. Disponível em<http://www.abed.org.br/censoead/censoEAD.BR 2012 pt.pdf>. Acesso em: 10 fev. 2014. 
FAVERO, R. V. M.; Dialogar ou evadir: Eis a questão! Um estudo sobre a permanência e a evasão na Educação a Distância, no Estado do Rio Grande do Sul. 2006. 167 f.

Dissertação (Mestrado em Educação). Porto Alegre: UFRGS, 2006.

LOBO, R. Leal et. al. A evasão no Ensino Superior Brasileiro. Cadernos de Pesquisa. Fundação Carlos Chagas: São Paulo, 2007.

MAIA, M. C.; MEIRELLES, F. S.; PELA, S. K. Análise dos Índices de Evasão nos Cursos Superiores a Distância do Brasil. FGV-EAESP, 2004. Disponível em: http://www.miniweb.com.br. Acessado em: 08 fev. 2014.

MAIA, M. C.; MATTAR, J. ABC da EAD: Educação a distância hoje. São Paulo: Editora Pearson Prentice, 2007.

RIBEIRO, M.; RIBEIRO, G. (org.). Educação em direitos humanos e diversidade: diálogos interdisciplinares. Maceió: EDUFAL, 2012.

SANTOS, E. M. dos. OLIVEIRA NETO, J. D. Evasão na Educação a Distância: identificando causas e propondo estratégias de prevenção. Revista Paidéi@, UNIMES VIRTUAL, Volume 2, número 2, dez. 2009. Disponível em:

<http://revistapaideia.unimesvirtual.com.br>. Acesso em: 23 fev. 2014.

SAVIANI, D. A nova lei da educação: trajetórias, limites e perspectivas. Campinas: Autores Associados, 2008.

TAVARES, C. Educar em direitos humanos, o desafio da formação dos educadores numa perspectiva interdisciplinar. IN: SILVEIRA, M. G. ET AL. Educação em direitos

humanos: fundamentos teórico-metodológicos. João Pessoa: Editora Universitária, 2007. 